\title{
MULTIDISCIPLINARY TEAM MEMBER CHALLENGES RELATED TO DISABLED \\ ADOLESCENTS' SOCIAL AND DOMESTIC \\ PROCESSES OF ADAPTATION
}

DOI: $10.24234 /$ se.2021.3.1.262

\begin{abstract}
AUTHORS' DATA:
Tatevik Ghazaryan, Occupational Therapist

Ministry of Labour and Social Affairs, Agency of Medical and Social Expertise

Lecturer, Khahatur Abovyan Armenian State Pedagogical University, Armenia

Contacts:ghazaryantatev56@aspu.am
\end{abstract}

\begin{abstract}
This study aims to identify and analyze the main difficulties and obstacles faced by multidisciplinary team members - specialists working in the field of rehabilitation while working with disabled adolescents.

A special questionnaire for data collection including open and closed-ended questions was developed. In face and online surveys were conducted with the members of the multidisciplinary team working with disabled adolescents in different rehabilitation centers and specialized institutions in 7 different regions of Armenia.

Detection, study, and evaluation of issues related to difficulties while performing daily activities by disabled adolescents due to the lack of appropriate tools do not allow specialists to carry out a systematic evaluation and monitor the process and progress. The other problem identified is related to the fact that most of the intervention organized in different centers is not continuous and systematic, as it is limited by unfavorable environmental conditions, lack of assistive devices and special equipment, as well as by the awareness and lack of knowledge of the specialists working in the field.
\end{abstract}

Keywords: multidisciplinary team, disabled adolescents, social and domestic adaptation, rehabilitation, assessment, intervention. 


\section{INTRODUCTION}

The problems of disabled adolescents cover almost all areas of health and social life, requiring a coordinated approach, close cooperation, and effective pooling of resources.

The social and domestic rehabilitation features of disabled adolescents are the restoration or compensation is connected with the loss of social and domestic skills due to illness, which is anticipated in daily activities of the adolescents. Due to the existence of adapted housing conditions, which should be comfortable, safe, as well as aimed at the adolescent's orientation, autonomy, ability to adapt to new conditions in life it is possible to improve the quality of life of disabled adolescents and to promote their maximum inclusion in family and public life.

The issue of providing services to disabled adolescents, in particular, assessment of social and domestic skills, requires mandatory professional intervention to ensure the necessary level of development of social and domestic skills of the latter.

\section{LITERATURE REVIEW}

Adolescence is a transitional stage of physical and psychological development that generally occurs during the period from puberty to legal adulthood (Macmillan Dictionary for Students, 1981; page 14). According to UNFPA (2013) terminology, adolescence is defined as follows: 10-14 years old is early adolescence, 15-19 years old - late adolescence. Still, there are many other different views on the age classification of adolescence.

According to the World Health Organization (WHO) classification, adolescence is defined as a period of 10-19 years old. WHO experts have described adolescence as a period of sexual development, from the emergence of secondary sexual characteristics to the stabilization of sexual behavior and reproductive function, when childhood psychological processes change to adult behavior; adolescents move from economic to social dependence to relative social independence (WHO, 2005).

This work is based on the classification suggested by well-known psychologist Elkonin, according to which there are distinguished two periods of adolescence: junior adolescence (12-14 years) and senior adolescence (early youth) age 15-17 years (Vigotskiy, 1984).

According to the DALY, the health problems of adolescents account for $15 \%$ of the worldwide health burden, which is a significant number in itself. Musculoskeletal disorders, 
asthma, gastrointestinal diseases, depression, neurosis, insomnia, etc. are more common among adolescents (Gore, et. al, 2011). At the same time, adolescence is not only a time of risks but also a time of opportunity. Adolescence is one of the most important stages of a person's life cycle, and adolescents are at a unique "crossroads of health" (Vigotskiy, 1984). Various biological and social factors in prenatal, early childhood, and school-age have an impact and predetermine the state of health in adolescence. It is not for nothing that Jean-Jacques Rousseau called adolescence "human the second birth" (Melkumova, Movsesyan, Sargsyan, Babloyan, 2019).

At the same, it is very important to state, that other diseases develop during adolescence, behavioral changes occur, which have a long-term effect on human health in adulthood. According to the WHO (2005), about $70 \%$ of premature deaths in adults are due to adolescent behavior. With such alarming data, attitudes and conceptual approaches to adolescent health issues have begun to change in many countries worldwide. Many adolescents do not have the experience or practice to seek medical help, which is largely due to health problems. As a result, the improvement in the health of young children in recent decades is far greater than the improvement in the health of adolescents. As a result, the improvement in the health of young children in recent decades is far greater than the improvement in the health of adolescents. The main indicators of the health of adolescents in Armenia follow the world trends (Melkumova, Movsesyan, Sargsyan, Babloyan, 2019). The results of the study reflect the fact that adolescents' health and health behaviour is influenced by various factors, including national traditions, transitional difficulties, the rapid intrusion of information technology into everyday life, etc. All of this has contributed to some of the health problems among children (Melkumova, Movsesyan, Sargsyan, Babloyan, 2019).

As mentioned above, the adolescence of children with disabilities can be influenced by several unique factors that are significantly associated with limitations. This can cause many painful experiences for a disabled adolescent. The situation is especially acute if a disabled adolescent is unable to manage his social behaviour and adapt to the social environment. Obvious differences in physical or mental standards at this age can lead to low self-esteem, negative selfattitude, and, consequently, the formation of a negative social positioning (Bauminger, 2002). Accordingly, it is possible for any specialist working with adolescents (boys and girls) to have a clear idea of the physical, sexual, and psychological characteristics of that age. And this circumstance becomes even more significant when it comes to the most common problems of social, domestic, development, health, educational issues of disabled adolescents. Depending on 
the type of disability, there are certain problems in the field of self-care, which are the cause of very serious complications. The person feels dependent and helpless. In this case, it is very important to ensure the adaptation process, as maximum conditions must be created for the person with a disability to be independent. It should be noted that in Armenia reality, the physical environment is still far from being accessible to people with disabilities, depending on the type of disability, in some situations people with disabilities may need constant help. It is very important for a person with a disability to be able to be independent by an adapted environment to regulate the daily activities of a person with a disability (Harutyunyan, 2017).

The problem of social and physical adaptation of adolescents with disabilities is one of the most important issues of the general inclusive system. Recently, this issue has become more urgent due to changes in attitudes towards people with disabilities. However, despite this, the process of adaptation of disabled adolescents in society remains almost unexplored, being crucially characterized by the effectiveness of comprehensive rehabilitation measures provided by professionals working with persons with disabilities (Harutyunyan, 2018). The most important issues related to the matter of disability are related to the existence of various social and physical barriers, which limit the active involvement and participation of disabled adolescents in public life. The current situation is the result of a wrong social policy, during which the system focuses only on a "healthy" society and reflects only the interests of this group of citizens. That is why effective activities, cultural life, leisure planning, and use of social services remain inaccessible and insurmountable for disabled adolescents. A more detailed study of social-physical rehabilitation technologies distinguishes two directions: social-domestic and social-environmental rehabilitation.

The process of helping a person who has suffered an illness or injury restore lost skills and so regain maximum self-sufficiency (Shiel, 2010). The concept of "rehabilitation" implies a system of measures, the purpose of which is the most complete recovery of the abilities of a child or adolescent with illness or disability and his/her return to an active life. Rehabilitation differs from conventional treatment in that it helps the adolescent to adapt optimally to the environment, and treatment in this context is understood as a process that has a greater impact on the body within the current situation. It is necessary to state that rehabilitation is more person-centered and futureoriented (WHO, 2020). Maximum rehabilitation impact and its efficiency are possible only through a multidisciplinary intervention approach. 
The peculiarity of social-domestic rehabilitation is reflected in the following definition: Creating a safe and comfortable living environment for independent living. Domestic living conditions play a big role in a person's life because domestic and household activities themselves are an integral part of a person's life. That is why the social-domestic conditions for the person must be comfortable and safe, correspond to all the standards of sanitation, living space, equipment, technical means of restoration.

Adaptation of housing conditions by the functional abilities of the disabled adolescent is a very important point in the process of rehabilitation. That means an installation of special auxiliary equipment and assistive devices, accessible daily activities, individual approach to each disabled adolescent, development of daily activities' plan, proposed by a multidisciplinary team, etc. In this regard, social-domestic rehabilitation includes social-domestic adaptation with sufficient assistive and adapted devices. While social-domestic orientation means recognition of the environment and needed equipment and devices.

Socio-environmental rehabilitation includes socio-environmental orientation, perception, and adaptation. Socio-environmental orientation is the process of developing the ability of a disabled adolescent to orientate in the concrete environment. Very often socio-environmental adaptation is designed for adolescents with mobility difficulties. Many authors address the issue of social adaptation of disabled adolescents. For instance, Voroshilova and others (2017) in their practical manual reflect the functional abilities of children with hand injuries aged 3-7 years, as well as the peculiarities of developing social and domestic skills through the use of the play method, considering it as the primary and main occupation of preschool children. The authors emphasize the role of developing the social and domestic skills necessary for self-care and daily life activities in the process of social adaptation of children with hand injuries. Statistics on the functional abilities and social skills of children with physical disorders demonstrate the effectiveness of play therapy in the early development of fine and gross motor skills (Voroshilova, et. al., 2017).

Shipicina and Mamaychuk (2004) in the methodological paper "Psychology of children with motor disorders" point out several problems that hinder the process of adaptation of children and adolescents with physical disorders. The authors particularly highlight the problems of differentiated psychological-pedagogical-medical-social care, the almost complete lack of professional qualification-training programs for specialists working with children with physical 
disorders, as well as the need for methodical elaboration of medical, psychological-correctivepedagogical work (Batisheva, 2012).

In conclusion, it can be stated that the problems of restricting the living activities of disabled adolescents can be solved by providing them with the daily occupation, social inclusion, and the main goal of professional activity is to support active activities within their capabilities, to protect people's right to participate in everyday public life as a full member of society.

\section{METHODOLOGY}

\section{Data collection}

An online survey was designed for the data collection within the frame of this study. Online data collection carries the potential of accessing a large and geographically distributed population, along with being time and cost-efficient for the researcher (Lefever, Michael \& Matthíasdóttir, 2006).

An open and closed questions questionnaire with 3 questions was designed to collect data from MDT members' perceptions about working with an adolescent with disabilities on housekeeping rehabilitation. It helps in focusing the respondent's attention on all the significant items (Bryman, 2012). As it is given in a written form, recording of the response from the respondents ensures uniformity.

\section{Participants}

Participants of the study are multidisciplinary team members working in different rehabilitation centres or organizations in 7 different regions in Armenia (Yerevan, Gegharqunik, Shirak, Ararat, Lori, Aragatsotn, Syuniq). The following organizations were included in the survey: "Emili Aregak” foundation, Specialized children's home of Kharberd, “Astghavard” centre for disabled children and parents, "Full life" NGO, Children's centre of Kapan, Rehabilitation centre of Kosh, "Luse” NGO.

200 multidisciplinary team (physical therapists, psychologists, speech therapists, special educators, art therapists, and other specialists) members took part in the face-to-face and online surveys. 
Table 1.

Demographic data of participants.

\begin{tabular}{|c|c|c|c|c|c|c|c|c|c|c|c|c|}
\hline \multirow{3}{*}{ MDT } & \multicolumn{4}{|c|}{ Sex } & \multicolumn{8}{|c|}{ Age } \\
\hline & \multicolumn{2}{|c|}{ Male } & \multicolumn{2}{|c|}{ Female } & \multicolumn{2}{|c|}{$20-29$} & \multicolumn{2}{|c|}{$30-39$} & \multicolumn{2}{|c|}{$40-49$} & \multicolumn{2}{|c|}{$50-59$} \\
\hline & $\mathrm{n}$ & $\%$ & $\mathrm{n}$ & $\%$ & $\mathrm{n}$ & $\%$ & $\mathrm{n}$ & $\%$ & $\mathrm{n}$ & $\%$ & $\mathrm{n}$ & $\%$ \\
\hline Physical therapist & 22 & 11 & 24 & 12 & 19 & 9 & 16 & 8 & 6 & 3 & 5 & 2 \\
\hline Psychologist & 36 & 18 & 2 & 1 & 21 & 10 & 16 & 8 & 1 & 1 & - & - \\
\hline Speech therapist & 39 & 20 & 2 & 1 & 20 & 10 & 13 & 7 & 5 & 2 & 3 & 2 \\
\hline Special educator & 30 & 15 & 2 & 1 & 17 & 8 & 9 & 5 & 2 & 1 & 4 & 2 \\
\hline Art therapist & 13 & 7 & 2 & 1 & 15 & 7 & - & - & - & - & - & - \\
\hline Other specialists & 25 & 12 & 3 & 1 & 18 & 9 & 3 & 2 & 1 & 1 & 6 & 3 \\
\hline Total & 165 & 83 & 35 & 17 & 110 & 53 & 57 & 30 & 15 & 8 & 18 & 9 \\
\hline
\end{tabular}

\section{Ethical considerations}

Taking into account the fact that currently there was no research ethics committee in the Republic of Armenia, gaining an official ethical license for the research was not possible. Participants were given the written information on the research aim, their rights, and the ethical obligations of the researcher. Also, informed consent was introduced to the participants. The names of the participants were kept anonymous and not used in the study.

\section{Data analysis}

A quantitative method of data collection and analysis was chosen in the current research as it allows to conclude the obtained data through certain numerical patterns, to put forward new hypotheses, or to confirm and refute the existing ones (Moss \& Hendry, 2002).

The strength of quantitative research is that no matter how many researchers conduct it, they will all come to the same conclusions, as the methods and methodologies for identifying social reality are accurate (Babbie, 2010). In this study, a standardized survey method belonging to a series of quantitative methods was used, the process of which is formal, the researcher interacts with the respondent to a minimum to have as little effect on his answers as possible (Babbie, 2010; Moss \& Hendry, 2002). That is, in this case, the purpose of the study is to measure le interpret the phenomenon through numbers. 
As a result, the answers received from the questionnaire were entered into the relevant software database (Microsoft Excel), where the collected data were analysed and the digital percentage points were presented.

\section{RESULTS}

During the planning and implementation stages of the research, the aim was to identify the main difficulties and obstacles faced by professionals in rehabilitating and adapting social and domestic skills while working with disabled adolescents.

Consequently, the results of the question "What are the main difficulties that you face while working with disabled adolescents?" have shown that $100(50 \%)$ of respondents mentioned the main reason for the existing difficulties lack special equipment in the centres where they work. Under the special equipment and devices, the multidisciplinary team members mean the need for various devices for personal use in everyday life, such as adapted dishes, furniture, kitchen appliances, which will promote the safe and independent involvement of disabled adolescents in the social process.

A bit smaller number of respondents $72(36 \%)$ have mentioned the main difficulty as unfavourable environmental conditions, environmental inaccessibility, for example, access to a nearby store, lack of ramps and handles, access and mobility for disabled adolescents with physical disorders. A significantly big number of participants 60 (30\%) mentioned the lack of practical skills and awareness as the main difficulty, in particular, emphasizing the need to know the latest methods, approaches, techniques to improve social skills, as well as the exchange of experience and the acquisition of relevant skills. Group of respondents 30 (15\%) consider features of mental development, such as difficulty concentrating, maintaining difficulties, managing behaviour, and so on as basic difficulties in their work. At the same time, $26(13 \%)$ respondents have mentioned other features of an adolescent with physical development, such as muscle tension, spasticity, difficulty in maintaining body position, moving, etc.

While concluding the analyses of the results it is possible to state the two most important points as main difficulties: unfavourable environmental conditions (1), and lack of practical skills and awareness (2). 
To the question "Are there special equipment, assistive devices in the institution where you work that facilitate or help to organize rehabilitation process more effectively?" 83 (41\%) of the respondents answered negatively, in addition to the negative responses, 37 (9\%) mention positively identifying adapted spoons and knives as main assistive devices. In the case of the concepts of "accessories", 13 (7\%) mentioned the presence of walkers and wheelchairs, and 33 $(16 \%)$ indicated the presence of jaws, trolleys, adapted knives, and knives.

In the framework of the current research, it was also necessary to find out and study the presence and availability of social and domestic skills intervention carried out in the abovementioned centres. As a result, $110(55 \%)$ of the surveyed specialists give positive responses and mentioned the activities performed. Those are shopping and finance management, cooking, serving. At the same time 48 (24\%) of respondents who work with disabled adolescents in their centres, have mentioned that all interventions including developing skills related to shopping, managing money, choosing and purchasing goods for everyday life, are not provided on systematic and continuous nature due to lack of financial resources and availability of necessary assistive devices. Also, it must be said that $52(26 \%)$ respondents mentioned that the centres carry out group work aimed at developing culinary skills, such as the planning and preparation of simple meals, in which case, as an obstacle, the specialists raised unfavourable environmental conditions, lack of specially adapted dishes, lack of equipment and modified environment.

And here are 100 of the interviewed specialists (50\%) who stated that their centers carry out activities aimed at developing self-care skills, in particular, certain interventions aimed at their self-participation in the self-care activities of adolescents with disabilities: washing, dressing, and eating (Figure 1).

As a result of the study of the implementation of work aimed at the development of social and domestic skills, it is considered possible to address all the shortcomings and difficulties encountered by professionals in the process of planning and implementation of the abovementioned intervention activities while working with disabled persons.

While reflecting on the question included in the survey questionnaire "What are the gaps or difficulties you face in the process of organizing work with disabled persons?" it is also very important to refer to tools for assessing the needs of disabled adolescents which are used or might be used by multidisciplinary team members. As a result of the research, according to the confirmed data, 180 (90\%) of the respondents mentioned the lack of a comprehensive need assessment toolkit 
as the main omission in the effective organization of work, providing at the same time stating that each of them, as an assessment tool, mainly uses observation, interview, and in some cases, questionnaires developed by them. At the same time, teaching and adaptation of effective socialdomestic skills, from the point of view of the intervention organization, requires a systemic, needbased, clearly developed, as well as planned impact. Still, 100 (50\%) of the respondents mentioned the lack of training of the multidisciplinary team members as a difficulty, interpreting it as a lack of experience in organizing social work, due to the lack of relevant literature, methodological guidelines, and in most cases, the absence of the mentioned foreword.

\section{Figure 1.}

\section{Distribution of performed social-domestic activities in different organizations.}

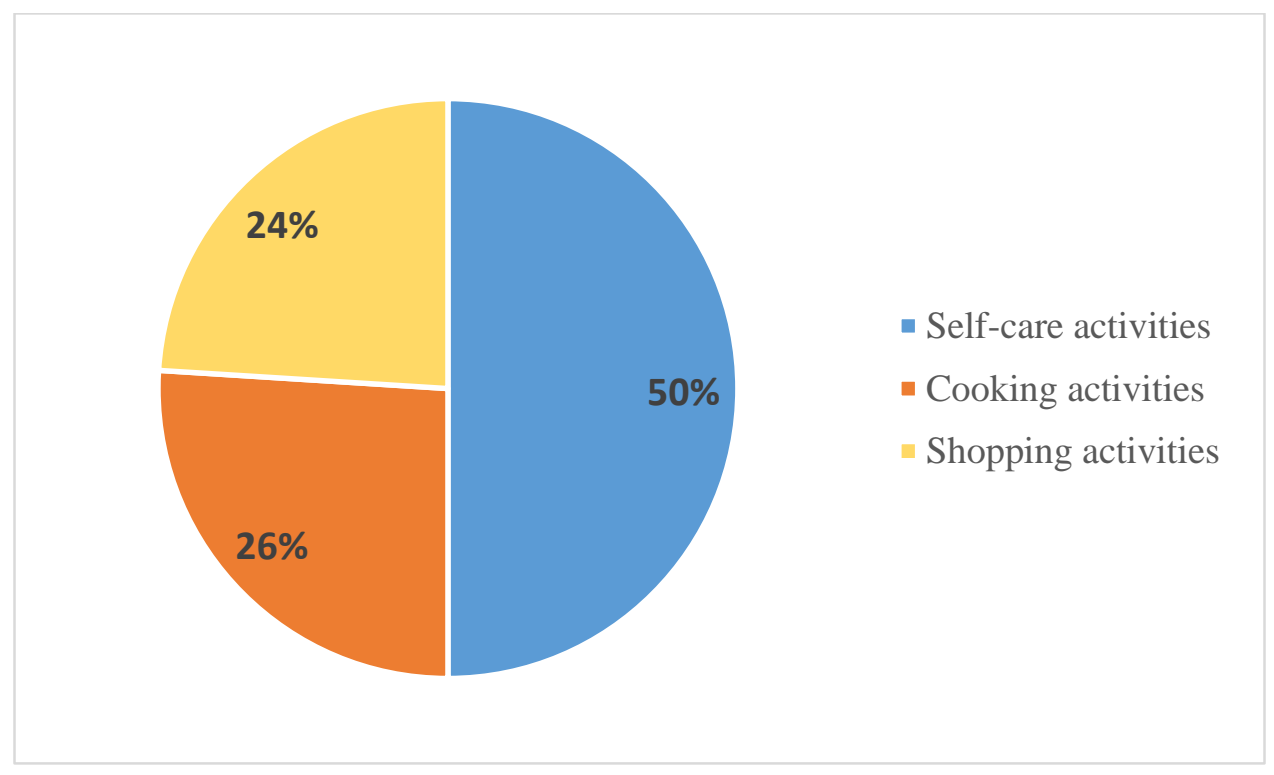

\section{DISCUSSION}

The few existing types of research on the social-domestic difficulties of disabled adolescents reflect the peculiarities of the adaptation process and have so far been conducted only in the framework of separate, exclusively foreign researchers by very few authors (Voroshilova, 2017; Batisheva, 2012).

Shipicina and Mamaychuk (2004) in the paper "Psychology of children with motor disorders" talk about a variety of problems that hinder the process of adaptation of adolescents with physical disorders. The authors particularly highlight the problems of differentiated 
psychological-pedagogical-medical-social care and issues connected with the preliminary and deep assessment that should be a milestone in rehabilitation work organized by all multidisciplinary team members. The result of this study identifies the same problems and thus proves their validity.

Thus, referring to the study of the organization and implementation of multidisciplinary teamwork in regards to social-domestic skill in the service centers, it should be noted that the identification of difficulties and problems related to the development of social-domestic skills of disabled adolescents, assessment and evaluation, identification of occupational performance issues due to the lack of appropriate tools does not allow specialists to carry out a systematic evaluation of more productive work and further monitoring. As a result, most of the work carried out is not continuous-systematic, as it is limited by unfavorable environmental conditions, assistive devices, special equipment, as well as by specialists due to lack of practical knowledge.

\section{CONCLUSION}

The peculiarities of the development of social skills and abilities of disabled adolescents require in-depth and comprehensive study. The job responsibilities of the multidisciplinary team members include the discovery of social and domestic abilities and skills, assessment and investigation, identifying strengths and weaknesses, as well as opportunities for adolescent life. All this is needed to organize future participation of the disabled adolescents in the abovementioned activities and clarification they need for implemented resources.

In the context of the conducted research work, it is possible to single out the following disadvantages: the small number of people who participated in the research (200 multidisciplinary team members). It is believed that if there were more numbers, the data received could have been more comprehensive, more reliable, more inclusive of information related to the research question.

The quantitative method of data collection and analysis was chosen within the frame of current research.

It is supposed that in the case of a combination of quantitative as well as qualitative methods, in addition to numerical indicators, our research would also have the qualitative features, patterns, differences of the data obtained by all the specialists who participated in the research, which showed the nature of the most comprehensive study of our work. 


\section{REFERENCE LIST}

1. Babbie, E., R. (2010). The practice of social research (12th ed.). Belmont, Calif: Wadsworth Cengage. ISBN 978-0-495-59841-1.

2. Batisheva, T., T. (2012). O detskom cerebralnom paraliche dlya roditeley pacientov, Metodicheskoe posobie, Moskva.

3. Bauminger, N. (2002). The Facilitation of Social-Emotional Understanding and Social Interaction in High-Functioning Children with Autism: Intervention Outcomes, Journal of Autism and Developmental Disorders, Vol. 32, p. 283-298.

4. Bryman, A. (2012). Social research methods (4th ed.). Oxford: Oxford University Press. ISBN 978-0-19-958805-3.

5. Gore, F., M., Bloem, P., J., Patton, G., Ferguson, J., Joseph, V., Coffey, C., Sawyer, S., M., \& Mathers, D. (2011). Global burden of disease in young people aged 10-24 years: a systematic analysis, The Lancet regional health; Published: June 07, DOI:https://doi.org/10.1016/S0140-6736(11)60512-6.

6. Harutyunyan, M. (2018). Transition to new life: when a disabled adolescent becomes an adult, Aktualniye nauchnie issledovaniya v sovremennom mire, Vipusk 2(34) Chast 9, ISSN 2524-0986, Fevral, sbornik nauchnikh trudov, str. 22-26.

7. Harutyunyan, M. (2017). WHO International Classification of Function as a disability determination model in Armenia, ISSN 2518-167X; Multidisciplinary scientific edition international academy journal Web of Scholar 5(14), August 2017, p. 54-57.

8. Lefever, S., Michael, D., \& Matthíasdóttir, Á. (2006). Online data collection in academic research: Advantages and limitations. British Journal of Educational Technology. 38. 574 $-582$.

9. Macmillan Dictionary for Students Macmillan, Pan Ltd. (1981), page 14, 456. Retrieved July 15, 2010.

10. Melkumova, M., Movsesyan, Y., Sargsyan, S., \& Babloyan, A. (2019). National Behavior in school-aged children of Armenia 2017/2018, National Study results, Yerevan, Arabkir Medical Centre - Institute of child and adolescents' health.

11. Moss, J. \& Hendry, G. (2002). Use of electronic surveys in the course evaluation, British journal of educational technology, 33, 5, 583-592. 
12. Moss, J. \& Hendry, G. (2002). Use of electronic surveys in course evaluation. Ontario: OISE/UT Trent Valley Centre.

13. Shiel, W. (2010). Rehabilitation, MedicineNet.

14. Shipicina, L., M., \& Mamaychuk, I., I. (2004). Psikhologiya detey s narusheniyami funkciy oporno-dvigatelnogo apparata, Moskva-Vlados.

15. UNFPA strategy on Adolescents and Youth, 2013.

16. Vigotskiy, L., S. (1984). Problema vozrasta// Sobr. soch.: V 6 т. M.: Pedagogika, 19821984. T. 4.

17. Voroshilova, E., L., Bazhanova, E., V., Deniskina, V., Z., Ignatova, I.,A., Koshechkina, T.,V., Maller, A.,R., Morozov, S.,A., Morozova, S.,A., Rechintskaya, E.,G., Solovyova, I.,L., \& Yakhnina, E.,Z. (2017). Organizaciya raboti po socialno-bitovoy adaptacii detejinvalidov. Uchebnoe posobie. - M.: FGAOU APK i PPRO,- $416 \mathrm{~s}$.

18. World Health Organization (WHO) (2020) Rehabilitation; https://www.who.int/newsroom/fact-sheets/detail/rehabilitation

19. World Health Organization (WHO) (2005) Adolescent Health; https://www.who.int/health-topics/adolescent-health\#tab=tab_1 